\title{
Fat acceptance as social justice
}

\author{
Cite as: CMAJ 2021 September 7;193:E1398-9. doi: 10.1503/cmaj.210772
}

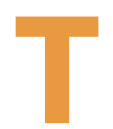

he fat body has long been a site of medical surveillance, and this has not changed during the COVID-19 pandemic. Early research focused on linking fatness with more severe disease outcomes, ${ }^{1}$ yet many have questioned the strength of this association, including within the pages of this journal. ${ }^{2,3}$

Fat communities, such as the National Association to Advance Fat Acceptance (NAAFA), have contested society's stubborn generalizations that associate fatness with disease and poor health outcomes, and push back against the assumption that fat people have little regard for themselves or their own well-being. They argue that thinking about obesity as a disease or medical risk (such as for severe COVID-19) contributes to stigma because it positions larger bodies as drains on an alreadytaxed health care system.

The NAAFA mobilizes the term "fat" in its fight against weight discrimination and fatphobia in all aspects of life, including in employment, health care and education. Similarly, as social scientists, we use the term "fat" rather than the deeply problematic medical term, "obesity," which causes harm to people under the guise of benign objectivity. Categories can shape how individuals view themselves, as philosopher Ian Hacking has argued; they reinforce judgments about people who do not conform to a norm. Thus, "obesity" is not merely a statistical category, but is rather an evaluation about what constitutes an ideal weight. To "fatten" a category, Mollow and McRuer explain, "means examining it through the lenses of fat studies and the fat justice movement." 4

Scholars of fat studies understand fatness as a way of thinking about bodily diversity. ${ }^{5}$ This literature maintains that fatness should be uncoupled from pathology, as such framings attach fatness to a sense

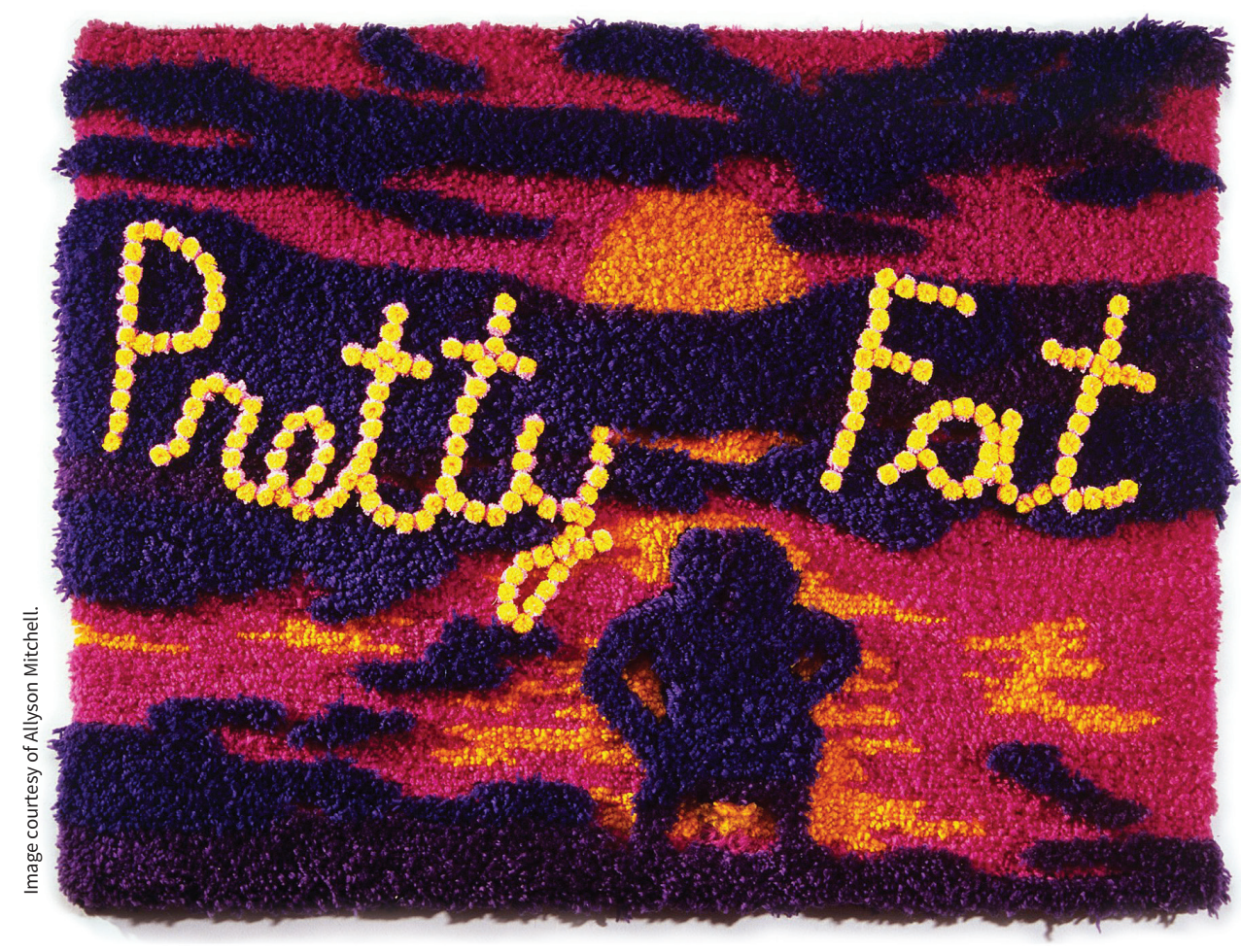

Pretty Fat by Allyson Mitchell (2006).

of moral weakness and failed citizenship, and can fuel stigma in various settings, even health care. ${ }^{6}$ Such an uncoupling is increasingly supported by medical and population health research, which suggests that people who are labelled obese are not necessarily unhealthy. ${ }^{7}$

Larger bodies have been associated with heightened health risks, chief among them rising rates of chronic illnesses such as diabetes, cardiovascular disease, hypertension, mental illness and some cancers. ${ }^{8}$ Early in the pandemic, research identified a link between larger- bodied patients and higher mortality rates from COVID-19, as well as more severe COVID-19 that required mechanical ventilation. ${ }^{9}$ As the authors of a recent meta-analysis on obesity and COVID-19 have cautioned, however, body weight may not be an independent predictor of poor health outcomes. ${ }^{10}$ Such findings are echoed by the recently developed Canadian Adult Obesity Clinical Practice Guidelines, which acknowledge the complex relation between weight and health, and link a person's overall health and well-being to health markers such as blood pressure and sugar levels, which can be normal in larger-bodied people. ${ }^{7}$ Thus, a fat person might be at risk of a particular health condition, but the move to think about a person whose body mass index categorizes them as obese, or worse, "morbidly obese," as generally unhealthy does little to promote the health of the person sitting in the doctor's office.

Scholars of fat studies also point to the ways in which obesity is racialized, as higher levels of obesity are often associated with already marginalized communities. This is particularly important for the medical profession, given that physicians and other allied health professionals have recently engaged in efforts to challenge the 
structural racism in health care experienced by Black, Indigenous and People of Colour (BIPOC) communities in Canada. ${ }^{11}$ The struggle for social justice is incomplete without serious attention to how fear, hatred and discrimination occur at the nexus of different identities, including among people labelled as obese. Fat studies scholars and activists have pointed to how the conflation of obesity with racialized and colonized communities is part of a long tradition of marking marginalized populations as diseased, and of associating pathology with Indigenous, Brown, Asian and Black bodies. ${ }^{12}$ As such, the surveillance and regulation of fat bodies must be understood in the context of colonialism and state regulation of Indigenous, Black and racialized communities. It is essential to think carefully and urgently about how "obese" bodies are treated as "risky" in this political moment, and to ensure that conversations about fatness are read with an appreciation for the realities of structural racism and the history ${ }^{13}$ of insufficient care for members of BIPOC communities.

How should physicians approach larger bodies in clinical settings? Physicians and health professionals should "fatten" their understanding of the complex factors associated with weight, and rethink some of the assumptions undergirding the association between weight and health by engaging with critical fat studies scholarship, as well as with fat activist perspectives, such as those advanced by the NAAFA. People who identify as fat should be understood as authoritative sources of knowledge, not passive recipients of occasional public or professional pity or sympathy. Physicians wield substantial power in the health care system - we are asking that doctors confront the possibility that how they interact with patients whose bodies are larger than the statistically ideal weight can harm their patient's psychological and emotional wellbeing, as well as their physical health, if these interactions discourage them from seeking health care in the future. As a prominent blogger who writes under the name "your fat friend" explains: "Perhaps the largest factor that kept me out of doctors' offices for eight long years was the relentless drumbeat of conversations about weight loss. Those conversations overwhelmingly ignored any history of eating disorders, food insecurity, and trauma. Often, health care providers skipped straight to a lecture without even asking about my current diet or activity levels. It felt like someone had pressed play on a recording, and I just had to wait it out." ${ }^{14}$

There are, however, no neat checklists for physicians who want to do better. Confronting fat stigma requires more than a list of do's and don'ts. It behooves those in the medical profession to resist suggesting that there are only a few bad apples, and that most doctors and other health care professionals treat their fat patients respectfully. Living in a culture that is consumed by feel-good narratives of weight loss and recovery means that few of us are immune to a series of embedded assumptions about fatness. And yet, like members of other marginalized communities, fat people deserve compassionate, competent care that is based on careful understandings of bodily difference and that respects their human rights.

\section{Deborah McPhail PhD}

Department of Community Health

Sciences, University of Manitoba,

Winnipeg, Man.

\section{Michael Orsini PhD}

Institute of Feminist and Gender Studies, School of Political Studies, University of Ottawa, Ottawa, Ont.

\section{References}

1. Obesity, race/ethnicity, and COVID-19. Atlanta: Centers for Diseases Control and Prevention; reviewed 2021 Mar. 22. Available: https://www. cdc.gov/obesity/data/obesity-and-covid-19.html (accessed 2021 July 16).

2. Duong D. Link between obesity and COVID-19 may not be what it seems. CMAJ 2021 June 25. Available: https://cmajnews.com/2021/06/25/ covid-obesity-1095952/ (accessed 2021 July 16).

3. Pausé C, Parker G, Gray L. Resisting the problematisation of fatness in COVID-19: in pursuit of health justice'. Int J Disaster Risk Reduct 2021 Feb. 21;54 [Epub ahead of print]. doi: 10.1016/j. ijdrr.2020.102021.
4. Mollow A, McRuer R. Fattening austerity. Body Politics 2015;3:25-49.

5. McPhail D, Mazur L. Medicalization, maternity, and the materiality of resistance: "maternal obesity" and experiences of reproductive care. In: Thickening Fat: Fat Bodies, Intersectionality, and Social Justice. New York: Routledge; 2019:46-62.

6. Rathborne JA, Cruwys T, Jetten J, et al. When stigma is the norm: How weight and social norms influence the healthcare we receive. $J$ Appl Soc Psychol 2020 June 14 [Epub ahead of print]. doi: 10.1111/jasp.12689.

7. Canadian Adult Obesity Clinical Guidelines. Edmonton: Obesity Canada. Available: https:// obesitycanada.ca/guidelines/ (accessed 2021 July 16).

8. Obesity and overweight [fact sheet]. Geneva: World Health Organization; 2021. Available: https://www.who.int/news-room/fact-sheets/detail /obesity-and-overweight (accessed 2021 July 16).

9. Belanger MJ, Hill MA, Angelidi AM, et al. COVID-19 and disparities in nutrition and obesity. N Engl J Med 2020;383:e69.

10. Yang J, Hu J, Zhu C. Obesity aggravates COVID-19: a systematic review and metanalysis. J Med Virol 2021;93:257-61.

11. Dryden $\mathrm{O}$, Nnorom $\mathrm{O}$. Time to dismantle systemic anti-Black racism in medicine in Canada. CMAJ 2021;193:E55-7.

12. Poudrier J. The geneticization of Aboriginal diabetes and obesity: adding another scene to the story of the thrifty gene. In: Obesity in Canada: Critical Perspectives. Toronto: University of Toronto Press; 2018:89-121.

13. Boyer $Y$. Healing racism in Canadian healthcare. CMAJ 2017;189:E1408-9.

14. Dear doctor, here's what fat patients need from you. Elemental 2020 Feb. 10. Available: https://elemental. medium.com/10-things-health-care-providers-can -do-to-better-treat-their-fat-patients-6ac7131eb20c (accessed 2021 July 16).

This article has been peer reviewed.

Acknowledgements: The authors thank the anonymous reviewers for helpful feedback, and Dorian Deshauser, CMAJ deputy editor, for shepherding this to publication.

Competing interests: Michael Orsini reports funding from the Social Sciences and Humanities Research Council of Canada. No other competing interests were declared.

Content licence: This is an Open Access article distributed in accordance with the terms of the Creative Commons Attribution (CC BY-NC-ND 4.0) licence, which permits use, distribution and reproduction in any medium, provided that the original publication is properly cited, the use is noncommercial (i.e., research or educational use), and no modifications or adaptations are made. See: https://creativecommons.org/ licenses/by-nc-nd/4.0/ 